\title{
A desobediência civil: "uma liberdade perigosa a uma servidão pacífica" no socius capitalista
}

\author{
PAULO ROBERTO SCHNEIDER ${ }^{1}$
}

Se estivesse de frente com Deleuze e ele me fizesse a pergunta "como haver entre as pessoas um laço revolucionário que mobilize a libido, Eros, o desejo, sem que deixe encerrá-lo em estruturas codificadas ou axiomatizadas de Édipo?", lhe responderia: a desobediência civil.

Afirmo com esse texto que a desobediência civil é uma "forma revolucionária" ou modo que passa por baixo das axiomáticas da ordem no capitalismo e que mantém a passagem de fluxos descodificados, positivos e revolucionários sem reconstituir famílias perversas, sem fazer reterritorialização/recodificação (DELEUZE; GUATTARI, 2010). Mahatma Gandhi (1869-1948) utilizou a desobediência civil como ferramenta anticolonialista em suas campanhas de 1930, seguido por Martin McLuther King Jr. (1929-1968) no movimento dos direitos civis norte-americanos na década de 1960 .

Esses são dois exemplos clássicos de desobediência civil que podem ser considerados como fluxos dentre os tantos que o socius capitalista tentará organizar (de pessoas, de recursos naturais, de excrementos, de alimentos, de reprodução, de parentesco, de sentimentos, fluxos míticos, religiosos, identitários, jurídicos, fluxos de morte, de doença, de prazer, de produtos, de trabalho, de capital...), depois de relevantes efeitos no seu interior. Mesmo que esse fluxo seja aprisionado/axiomatizado, podemos considerar que há a produção de mecanismos contra a axiomática por meio da organização de atos pelos quais as pessoas simplesmente vão a público não cumprindo uma determinada lei, mas, de modo esquizo, pretendem embaralhar os códigos legais. Dentre os casos mais recentes, destacamos um caso famoso de desobediência civil que mais se aproxima da categoria (que assim chamamos) "ataque ao capitalismo financeiro": o ataque operado por Eric Durán às instituições financeiras, na Espanha, em 2008. Como destaca o artigo de Paul Geddis (2013), na revista eletrônica VICE, que

[...] em 2008, o ativista anticapitalista Enric Durán pegou emprestado $€ 492.000$ (cerca de R\$1.260.0oo) de 39 entidades financeiras sem nenhuma intenção de devolver essa grana. Mas, (...) ele não gastou tudo... Ao invés disso, ele aplicou o dinheiro em várias causas anticapitalistas não especificadas e gastou o resto com o Crisi,

\footnotetext{
${ }^{1}$ Doutorando em Filosofia (2016) pela UNIOESTE/Campus de Toledo/PR. Participa do Grupo de Pesquisa "Escrileituras da diferença em filosofia-educação" oriundo do Projeto interinstitucional (UFRGS, UNIOESTE, UFPEL, UFMT) "Escrileituras: um modo de ler-escrever em meio à vida", (20112014) do Programa Observatório da Educação DEB/CAPES/MEC. Foi Bolsista do Projeto Escrileituras: um modo de ler-escrever em meio à vida (MEC - CAPES/OBEDUC/INEP) entre janeiro de $2013 \mathrm{e}$ dezembro de 2014. E-mail: pauloschneiders@gmail.com
} 
um jornal gratuito que detalha como ele fez isso e incentiva outras pessoas a fazer o mesmo.

A iniciativa de Durán vai mais longe ao publicar um artigo na sua revista CRISI, intitulado Acció directa financera, em que afirma: "Eu roubei $€ 492,000$ euros de quem mais nos rouba, para denunciá-los e construir algumas alternativas viáveis para a sociedade". Nesse artigo, explica que queria, com isso, chamar a atenção para o sistema financeiro bizarro que vivemos, onde "é impossível normalmente pra qualquer pessoa conseguir essa soma de dinheiro e, mesmo assim, os empréstimos estão aí, super facilitados e tributados" (DURÁN, 2008, p. 10). Além dessas declarações, o ativista oferece muitas possibilidades de take action, para quem queira se engajar e viabilizar uma construção alternativa ao modus operandi financeiro atual: “- não pegue nenhum empréstimo e tire todo o dinheiro de bancos". Já em entrevista a Paul Geddis, colunista da Revista VICE, explica que:

Queríamos usar o dinheiro para um projeto que pudesse provar como diferentes métodos de capitalismo são possíveis. Isso foi entre o verão de 2005 e a primavera de 2008 - aproximadamente três anos. Aprendi como o sistema de empréstimos funcionava e as informações em que os bancos confiavam para concedê-los. Aprendi sobre os buracos no sistema e como passar por eles. No começo eu conseguia um empréstimo para cada três requisições, no final eu já conseguia nove empréstimos a cada dez pedidos. Por exemplo, um dos buracos do sistema é que o Banco da Espanha compartilha as informações de crédito com outros bancos, mas só para empréstimos acima de $€ 6.000$ [em torno de $\mathrm{R} \$ 15.000]$. Então só pedi empréstimos abaixo desse valor por dois anos, movimentando fundos sem ter o Banco da Espanha controlando minhas ações (DURÁN apud GEDDIS, 2013, s.p).

Na sua revista, a CRISI (2008), explica como gastou o dinheiro que afanou sistematicamente: não tomou tudo para si, mas, como já dissemos, para arcar os custos com a publicação da revista, além de doar para instituições que buscavam alternativas ao sistema capitalista e a criação de uma cidade completamente autônoma nos arredores de Barcelona. Vemos novos fluxos em erupção indo ao externo do próprio capitalismo financeiro; é o que podemos chamar, com Deleuze e Guattari, de uma esquizofrenia ou um puro processo de fluxos descodificados.

Nos chama a atenção essa tentativa de Durán contra a prerrogativa de regulação ou regulamentação dos fluxos, do qual tratam Deleuze Guattari (2010, p. 334):

esses fluxos exigem órgãos sociais de decisão, de gestão, de reação, de inscrição, uma tecnocracia e uma burocracia que não se reduzem ao funcionamento de máquinas técnicas. Em suma, a conjunção dos fluxos descodificados, suas relações diferenciais e suas múltiplas esquizas ou fraturas, exigem toda uma regulação cujo principal órgão é o Estado [capitalista], ...[ao qual] o campo de forças sociais, passa a seu serviço e serve de regulador aos fluxos descodificados e 
axiomatizados.

No capitalismo, todo processo de fluxos terá o seu limite, a sua contradição pela criação de limites internos. O desejo-Duran foi capturado, cassado e preso por dois meses em 2011, mas logo foi libertado até o julgamento (que não acontecera de imediato, pois seu advogado se recusara a representá-lo e, assim, não há como manter um julgamento, graças à desobediência de alguns burgueses iluministas). Sendo convocado para comparecer à corte, Durán foge das autoridades jurídicas do capitalismo usando de uma estratégia bem interessante: não há advogado que o defenda. Sem advogado, não haverá condições de defesa, logo, não há como ser sentenciado ao no mínimo oito anos, segundo a Justiça espanhola. O processo que Durán terá de responder serve de exemplo à verdadeira noção de axiomática capitalista, à qual tentará escapar e escapar, mas sempre tendo que prestar contas infinitamente. $\mathrm{O}$ processo de desobediência criado por Durán está para a ordem do que tenta escapar ao capitalismo mostrando seus limites internos, mas, por outro lado, já que o papel da axiomática será o de contrariá-lo, haverá uma nova descodificação dos fluxos. Tudo o que tenta escapar é substituído por novos limites, colocados no lugar. As instituições financeiras não toleram desobediências; ocorrerá uma nova axiomática para conter o que tentará fugir do capitalismo financeiro.

De certo modo, nada escapa à axiomatização, inclusive a desobediência civil. Tudo no socius capitalista retorna a Édipo: "o que começa sendo glorioso, logo começa a escorrer sujeira. O que começa como uma espécie de canto de vida e que era, então, revolucionário - pois não vejo algo que seja revolucionário e que não seja um canto de vida -, se transforma em uma imunda cultura da morte" (DELEUZE; GUATTARI, 2010, p. 106). Mas, o que se pretende afirmar é a desobediência civil como uma matéria infinita, ligada à multiplicidade e, para a esquizoanálise, não alcançada por limites ou finitudes que o sistema capitalista (financeiro, no caso Durán) pretende lhe mostrar, ou seja, os limites internos a tudo o que se pretenda criar: um ato de desobediência que era tirar o dinheiro dos bancos e investir em projetos anticapitalistas.

Um movimento como esse terá sucesso porque percebe que é preciso afetar o nervo central de um sistema que tem ligações profundas entre o financeiro, a política, as multinacionais e os governos. O capitalismo é global e é financeiro, não há de se duvidar, mas também não se pode ignorar que ele é falível. A crise econômica mundial, todavia, não parece afetar a alguns, os proprietários do capital financeiro. Mas como atingi-los? De certo modo, a descontinuidade do fluxo de dinheiro será uma estratégia que estanque a máquina empréstimo, como vemos ocorrendo agora, no Brasil. No caso Durán, esse fluxo será estancado por um motivo mais significativo, cujos objetivos principais são: primeiro, denunciar o sistema financeiro como insustentável e, segundo, que é possível a desobediência, a coragem de modo que forme um agenciamento coletivo financeiro como um modus, mesmo que não se 
extinga o capitalismo, mas que permita mostrar suas falhas. Nas palavras de Durán, em entrevista à VICE (2013):

O dinheiro era investido. Nunca tive mais de $€ 50.000$ [em torno de $\mathrm{R} \$ 130.000]$ comigo. Tudo foi gasto em vários projetos. (...) ficou claro que os bancos não estavam interessados para onde esse dinheiro foi. Não houve nenhuma investigação e, como isso era uma ação política, eles queriam reprimir só a mim e não ao coletivo. Eles não queriam transformar isso em algo maior do que já era. Passei muito tempo imaginando como colocar essa história em domínio público. Eu queria que isso alcançasse o maior número possível de pessoas, mas fiquei preocupado em ser reprimido. Então decidi usar um pouco do dinheiro para publicar o jornal [Crisi] e acho que foi uma das melhores decisões que tomei ${ }^{2}$.

Com as palavras de Durán percebemos que a desobediência civil tem características de um agenciamento coletivo no tecido social (DELEUZE; GUATTARI, 2010, p. 482). A axiomática do Estado é contestada pela desobediência, levando a um processo amiúde de desterritorialização dos códigos pelos fluxos, especialmente porque o que se pretende é a modificação na ordenação que se coloca: "se descobre não em uma crítica social codificada e territorial, mas em uma decodificação, em uma desterritorialização" (2010, p. 89). No caso da desobediência operada por Martin Luther King, a defesa dos direitos civis dos negros; de Ghandi, contra a prepotência

\footnotetext{
${ }^{2}$ A mídia viu que esse jornal estava sendo distribuído de graça nas ruas e eles não queriam ficar de fora de algo que estava sendo falado por toda parte, então publicar meu próprio jornal realmente ajudou a mensagem a chegar até a mídia mainstream. Bom, muitas pessoas já estão fazendo isso por acidente; deixar de pagar seus débitos foi uma das coisas que derrubou o sistema financeiro em primeiro lugar. Não tanto com pequenos empréstimos ou hipotecas particulares, mas com grandes companhias de construção e desenvolvimento que não puderam pagar suas dívidas e acabaram falindo. A chance do plano geral se tornar global não é muito provável, mas o importante é espalhar a ideia de pequenas mudanças e decisões que você pode tomar para ajudar o mundo a se tornar um lugar melhor. "Prefiro uma liberdade perigosa a uma servidão pacífica". É, isso é uma questão de agir de maneira consistente com o que você sente e fazer o que é melhor, mesmo que as autoridades queiram que você faça de outro jeito. Seria interessante começar um debate sobre a eficiência do sistema judiciário e questionar como ele funciona. Trata-se de um sistema de prisão que não ajuda ninguém - nem as vítimas e muito menos os presos ou o governo, que são aqueles que precisam pagar por tudo. É tempo de repensar e criar algo novo, certo? (...) O principal é que estamos construindo outro sistema desde o começo. É um sistema aberto, o que significa que ninguém vai obrigar você a ser parte disso. Podemos reformular tudo com essa liberdade e decidir como queremos que sejam os sistemas de saúde e educação, a economia, os conflitos e muitas outras coisas. Já estamos colocando isso em prática através da Cooperativa Integral Catalã (CIC) e outros projetos associados É uma assembleia onde construímos uma economia comum, organizamos o consumo, cobrimos as necessidades, organizamos todo o trabalho e estabelecemos relações financeiras para apoiar novos projetos produtivos. Temos uma infraestrutura para cobrir saúde, moradia, necessidades básicas de alimentação, transporte, energia - o básico. $O$ ponto principal é que isso funciona com base na autonomia. O que precisamos são mudanças profundas nas relações humanas, confiança entre as pessoas. A revolução integral não é sobre mudar o sistema econômico, é sobre mudar tudo, mudar o ser humano. Estamos falando de mudanças em todos os aspectos da vida. A maior questão aqui é que o conceito de partidos políticos contradiz o conceito de assembleia. A assembleia é um processo aberto que funciona através do consenso. O sistema político de partidos, por outro lado, é baseado em confrontação [DURÁN em entrevista a GEDDIS, 2013; os grifos são meus].
} 
dos colonizadores britânicos e; de Durán, contra o monopólio financeiro pelas instituições, se evidencia que o Estado não foi posto em causa, mas sim que se pretenda reformá-lo. Mesmo o que se torna possível com o laço da desobediência pode ser capturado ou territorializado novamente pelo Estado, mas, ainda assim, sem dúvida, não poderá impedir que novos fluxos tendam a vazar.

\section{Referências}

DELEUZE, Gilles; GUATTARI, Félix. O Anti-Édipo: Capitalismo e Esquizofrenia 1. Trad. Luiz B. L. Orlandi. São Paulo: Ed. 34, 2010.

DURÁN, Eric. Acció directa financera. [on-line]. Revista CRISI. Edição 1. Barcelona: Impressão própria, 2008. Disponível em: http://enricduran.cat/premsa/. Acesso em: 13/05/2017.

GEDDIS, Paul. Esse Cara Pegou um Empréstimo Gigante para Destruir o Sistema Financeiro. VICE, 2013. Disponível em: http://www.vice.com/pt_br/read/esse-carapegou-um-emprestimo-gigante-para-destruir-o-sistema-financeiro. Acesso em: $13 / 05 / 2017$.

Submissão: 15.05.2017 / Aceite: 14.06.2017 